\title{
Congenital Arteriovenous Fistula
}

National Cancer Institute

\section{Source}

National Cancer Institute. Congenital Arteriovenous Fistula. NCI Thesaurus. Code C35377.

An abnormal, epithelial-lined connection between an artery and vein that is present at the time of birth. 